\title{
Covarying patterns of white matter lesions and cortical atrophy predict progression in early MS
}

Muthuraman Muthuraman, PhD, * Vinzenz Fleischer, MD,* Julia Kroth, MD,* Dumitru Ciolac, MD, Angela Radetz, MSc, Nabin Koirala, PhD, Gabriel Gonzalez-Escamilla, PhD, Heinz Wiendl, MD, Sven G. Meuth, PhD, MD, Frauke Zipp, MD, † and Sergiu Groppa, MD†

Neurol Neuroimmunol Neuroinflamm 2020;7:e681. doi:10.1212/NXI.0000000000000681
Correspondence

Dr. Groppa

segroppa@uni-mainz.de

\section{Abstract}

\section{Objective}

We applied longitudinal 3T MRI and advanced computational models in 2 independent cohorts of patients with early MS to investigate how white matter (WM) lesion distribution and cortical atrophy topographically interrelate and affect functional disability.

\section{Methods}

Clinical disability was measured using the Expanded Disability Status Scale Score at baseline and at 1-year follow-up in a cohort of 119 patients with early relapsing-remitting MS and in a replication cohort of 81 patients. Covarying patterns of cortical atrophy and baseline lesion distribution were extracted by parallel independent component analysis. Predictive power of covarying patterns for disability progression was tested by receiver operating characteristic analysis at the group level and support vector machine for individual patient outcome.

\section{Results}

In the study cohort, we identified 3 distinct distribution types of WM lesions (cerebellar, bihemispheric, and left lateralized) that were associated with characteristic cortical atrophy distributions. The cerebellar and left-lateralized patterns were reproducibly detected in the second cohort. Each of the patterns predicted to different extents, short-term disability progression, whereas the cerebellar pattern was associated with the highest risk of clinical worsening, predicting individual disability progression with an accuracy of $88 \%$ (study cohort) and $89 \%$ (replication cohort), respectively.

\section{Conclusion}

These findings highlight the role of distinct spatial distribution of cortical atrophy and WM lesions predicting disability. The cerebellar involvement is shown as a key determinant of rapid clinical deterioration. 


\section{Glossary}

AUC $=$ area under the curve; EDSS = Expanded Disability Status Scale; FLAIR = fluid-attenuated inversion recovery; FWHM = full width at half maximum; GM = gray matter; ICA = independent component analysis; LST = lesion segmentation toolbox; MNI = Montreal Neurological Institute; MP-RAGE = magnetization-prepared rapid gradient-echo; MSFC = MS Functional Composite; $\mathbf{R O C}=$ receiver operating characteristic; $\mathbf{R R M S}=$ relapsing-remitting MS; $\mathbf{S V M}=$ support vector machine; $\mathbf{W M}=$ white matter.

MS is a chronic neuroinflammatory disease of the CNS that leads to progressive disability in young adults. Acute inflammation and chronic neuronal cell loss contribute differently to disease progression and disability. ${ }^{1,2}$ Cortical gray matter (GM) atrophy starts at or before clinical disease onset, and the initial extent has robust associations with functional deterioration and cognitive impairment. ${ }^{3}$ It reliably predicts and is a relevant marker of disease progression. ${ }^{4,5}$ Along with cortical GM atrophy, inflammatory, demyelinating white matter (WM) lesions are considered as primordial hallmarks of the disease, and their quantity at the beginning of the disease is associated with future clinical outcome. ${ }^{6}$ Furthermore, lesion extent at disease onset is the most important conventional MRI feature in the clinical setting that reliably predicts long-term disability. ${ }^{7}$

In the advanced stages of the disease, GM and WM damage patterns have been studied independently of each other and have each been shown to be associated with motor dysfunction or cognitive impairment. ${ }^{8-10}$ Because both GM and WM damage affect disease-related disability, integrating analysis of these 2 compartments should provide more accurate predictive models for disease progression.

In our study, we investigated distinct topological patterns of cortical GM atrophy and WM lesions in patients with early MS and assessed the relevance of these patterns for disease progression. First, we used parallel independent component analysis (ICA) to examine whether cortical atrophy and WM lesions, derived from standardized 3T MRI, follow specific patterns in relation to each other. This methodological approach has recently been successfully implemented in the exploration of GM and WM integrity in other neurodegenerative and psychiatric disorders to depict patterns of specific tissue abnormalities. ${ }^{11,12}$ Then, we investigated whether the identified patterns were associated with disease progression in terms of cortical atrophy and clinical disability after 1 year of follow-up. To confirm the reliability of our results, we replicated the analysis in an independent cohort of patients with MS.

Previous studies investigating GM and WM damage commonly used conventional lesion and atrophy measures capturing both aspects of the disease, inflammation and neurodegeneration, but did not take mutual pattern recognition analysis into account. ${ }^{13-15}$ Our hypothesis was that covarying patterns of GM atrophy and WM lesions derived from structural MRI at disease onset could accurately predict disability over time.

\section{Methods}

\section{Study participants and design}

In this longitudinal study, a cohort of 119 patients with early relapsing-remitting MS (RRMS) with a maximum disease duration of 5 years was included. ${ }^{16} \mathrm{~A}$ diagnosis of RRMS was established according to the 2010 revised McDonald diagnostic criteria. ${ }^{17}$ To verify the reliability of the obtained results from the main study cohort, we replicated the analyses by including an independent data set of a replication cohort of 81 patients with RRMS from another medical center. All patients underwent clinical evaluation, including the Expanded Disability Status Scale (EDSS) scoring and MRI examination, and were clinically and radiologically followed up after 12 months. Patients were relapse- and steroid-free for at least 3 months before the MRI scans. Patients were considered to have disease progression if they had an increase of at least 1 point in the EDSS score at follow-up compared with baseline. Patients having a decrease, no increase, or an increase of 0.5 in the EDSS score were considered to have no progression. ${ }^{18}$

Both MS cohorts were retrospectively analyzed from a prospective longitudinal observational study between 2011 and 2016 comprising yearly follow-up assessment with a standardized protocol. The minimal requirements for inclusion in our 2 cohorts were a standardized MRI with concomitant clinical assessment and a follow-up after 12 months ( \pm 3 months). Dropout rates between both cohorts were comparable (study cohort: $12 \%$ vs replication cohort: $9 \%$ ).

\section{Standard protocol approvals, registrations, and patient consents}

The study was approved by the local medical ethics committee (approval number 837.543.11 [8085]); all patients provided informed consent in accordance with the Declaration of Helsinki.

\section{MRI data acquisition}

\section{Study cohort}

Imaging was performed on a 3T MRI scanner (Magnetom Tim Trio, Siemens, Germany) with a 32-channel receive-only head coil using a sagittal 3D T1-weighted magnetization-prepared rapid gradient-echo (MP-RAGE) sequence (echo time/ inversion time/repetition time $=2,52 / 900 / 1,900 \mathrm{~ms}$, flip angle $=9^{\circ}$, field of view $=256 \times 256 \mathrm{~mm}^{2}$, matrix size $=256 \times 256$, slice thickness $=1 \mathrm{~mm}$, voxel size $=1 \times 1 \times 1 \mathrm{~mm}^{3}$ ) and a sagittal 3D T2-weighted fluid-attenuated inversion recovery 
(FLAIR) sequence (echo time/inversion time/repetition time $=388 / 1,800 / 5,000 \mathrm{~ms}$, echo-train length $=848$, flip angle $=$ $120^{\circ}$, field of view $=256 \times 256 \mathrm{~mm}^{2}$, matrix size $=256 \times 256$, slice thickness $=1 \mathrm{~mm}$, voxel size $=1 \times 1 \times 1 \mathrm{~mm}^{3}$ ).

\section{Replication cohort}

Patients from the replication cohort were scanned with a 3T MRI (Magnetom Prisma ${ }^{\text {fit }}$, Siemens, Germany) scanner with the following acquisition parameters: a sagittal 3D T1weighted MP-RAGE (echo time/inversion time/repetition time $=2,2 / 900 / 2,130 \mathrm{~ms}$, flip angle $=8^{\circ}$, field of view $=256 \times$ $256 \mathrm{~mm}^{2}$, matrix size $=256 \times 256$, slice thickness $=1 \mathrm{~mm}$, voxel size $\left.=1 \times 1 \times 1 \mathrm{~mm}^{3}\right)$ and a sagittal 3D T2-weighted FLAIR (echo time/inversion time/repetition time $=389 /$ $1,800 / 5,000 \mathrm{~ms}$, echo-train length $=250$, flip angle $=120^{\circ}$, field of view $=256 \times 256 \mathrm{~mm}^{2}$, matrix size $=256 \times 256$, slice thickness $=1 \mathrm{~mm}$, voxel size $=1 \times 1 \times 1 \mathrm{~mm}^{3}$ ).

In both cohorts, the acquired T1-weighted images were then processed by using an automated processing pipeline to extract cortical atrophy over 1 year and the T1- and T2-weighted FLAIR images for the lesion growth algorithm of WM lesion volumes.

\section{MRI data processing}

\section{Quantification of WM lesion volume}

The baseline and follow-up volumes of WM lesions were estimated by applying the cross-sectional pipeline of the lesion segmentation toolbox ${ }^{19}$ as part of the Statistical Parametric Mapping (SPM8) software. Initially, 3D FLAIR images were coregistered to 3D T1-weighted images and bias corrected. After partial volume estimation, lesion segmentation was performed with 20 different initial threshold values for the lesion growth algorithm. The optimal threshold ( $\mathrm{K}$ value, dependent on image contrast) was determined for each patient and an average value for all patients calculated. Afterward, for automatic lesion volume estimation and filling of $3 \mathrm{D}$ T1-weighted images, a uniform $\mathrm{K}$ value of 0.1 was applied in all patients. Subsequently, the filled 3D T1-weighted images and the native 3D T1-weighted images were segmented into GM, WM, and CSF and normalized to Montreal Neurological Institute (MNI) space. Finally, the quality of the segmentations was visually inspected to increase reliability.

\section{Cortical thickness reconstruction}

After filling of T1-weighted hypointense lesions, the construction of cortical surface and subcortical volume estimation for each patient was performed based on 3D T1-weighted images using FreeSurfer version 5.3.0 (surfer.nmr.mgh.harvard.edu) in a fully automated fashion, followed by visual inspection for quality control at various processing steps. Most of the patients' MRIs from both cohorts had sufficient quality and required no additional intervention after initial automated processing. Only a few patients with excessive or insufficient skull stripping affecting the surface reconstruction were reran after manual restoration of missing tissue or deleting nonbrain tissue. Technical details of the processing stream for surface-based reconstruction were previously described and validated. ${ }^{20,21}$ Briefly, this automated processing pipeline is based on the creation of an unbiased within-subject template space and image using a robust inverse consistent registration. ${ }^{20}$ The unbiased template serves for initialization of skull stripping, Talairach transformation, atlas registration, and parcellation for each subject's time points. ${ }^{21}$ Surface maps of regional rates of cortical thickness atrophy (in $\mathrm{mm} / \mathrm{y}$ ) were computed as (thickness at time point 2 - thickness at time point 1 )/(time point 2 [years] - time point 1 [years]) and smoothed with a $10-\mathrm{mm}$ full width at half maximum (FWHM) Gaussian kernel. An appropriate smoothing level increases the sensitivity of subsequent statistical analysis. ${ }^{22}$ We used 10-mm FWHM because larger smoothing lowers the spatial resolution of cortical thickness measurements. ${ }^{23}$ Subsequently, within each of the detected lesion patterns, differences in rates of cortical atrophy between the groups (classified according to the lesion volume of the pattern) were evaluated. Generated statistical parametric maps of significant group differences were corrected for multiple comparisons using the false discovery rate $(p<0.05)$ method.

\section{Identification of cortical GM atrophy and WM lesion patterns: parallel ICA}

ICA allows the identification of hidden noncorrelating components that underlie sets of measurements without any previous knowledge of the data. In this study, we used the parallel ICA algorithm implemented in the fusion ICA toolbox. ${ }^{24}$ The purpose of parallel ICA is to discover independent components from 2 inputs, here, the rate of cortical atrophy and the volumes of baseline WM lesions derived from the MRI of the same patient, in addition to the relationship between them. Before inputting into ICA, cortical atrophy maps (registered in the halfway space of the FreeSurfer longitudinal pipeline) were transformed into MNI space to ensure their fitting with the WM lesion maps. The association between the influences of the cortical atrophy rate on the WM lesion volume was calculated with the algorithm by estimating the correlation between the rate of cortical atrophy and the WM lesion volume. Parallel ICA optimization is based on the Infomax algorithm, ${ }^{25}$ which maximizes the mutual entropy to enhance the independence between the components for the 2 inputs. Finally, to avoid overfitting because of too many estimated parameters, the learning rate of the correlation term is adaptively adjusted. ${ }^{26}$ To determine the correct number of independent components, a modified version of the Akaike information criterion proposed by Li et al. ${ }^{27}$ was applied. The components from each modality were selected to be the correlations with the highest significance. First, we used the Akaike information criterion to estimate the number of components and then to reduce the component number to reach a consistent level among the different runs. An overview of the analysis is illustrated in figure 1 . In a further analysis, we used the Buckner functional cerebellar connectivity atlas, which parcellates the cerebellum into 7 functional zones that are coupled to cerebral cortical regions (visual, somatomotor, dorsal attention, ventral attention, limbic, frontoparietal, and default network). ${ }^{28,29}$ This atlas depicts the organization of cerebro-cerebellar circuits and delimits the 
A

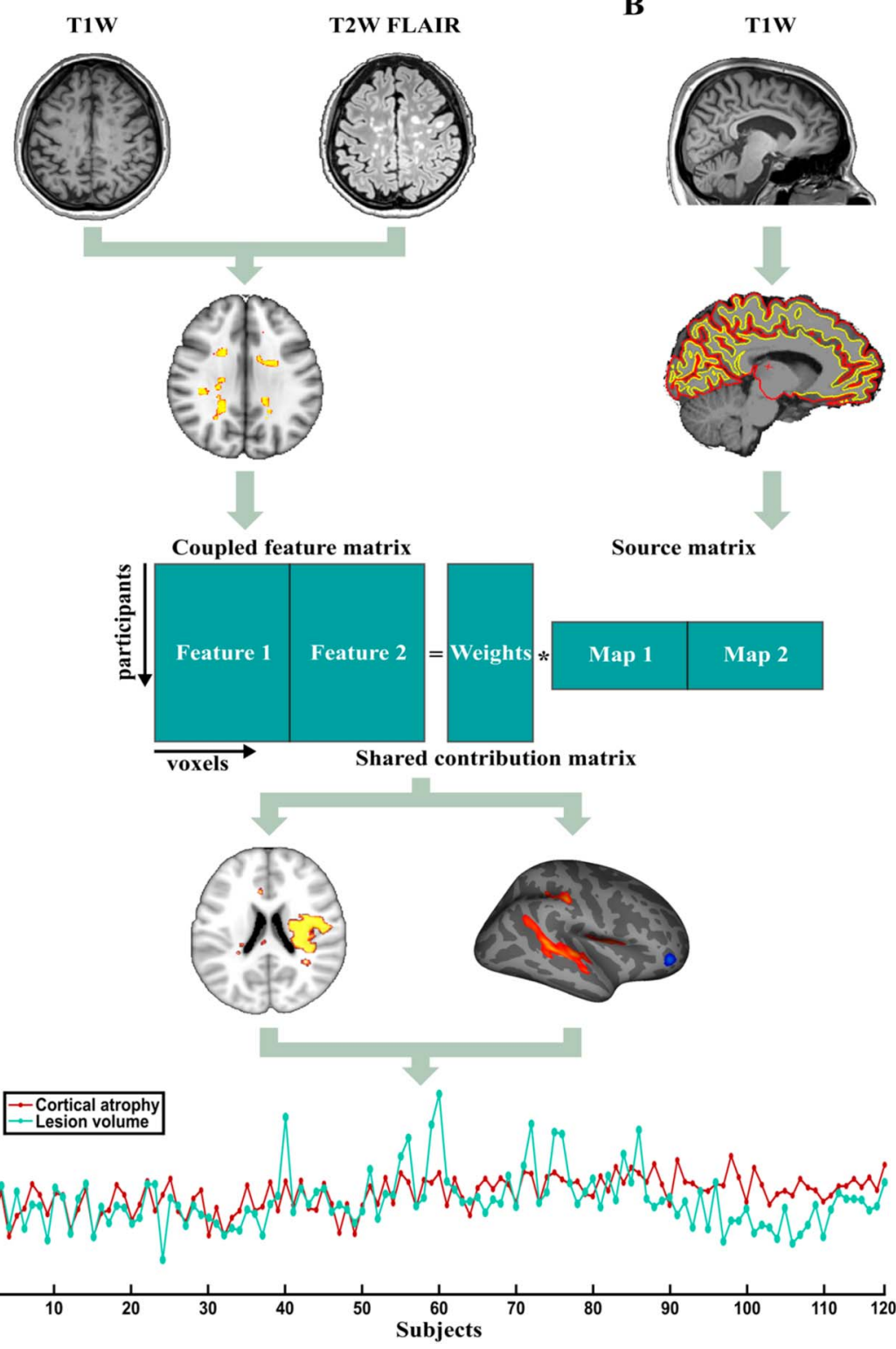

(A) WM lesion volumes derived from structural MRI data sets (T1W, T2W FLAIR) and (B) cortical atrophy rates (FreeSurfer processing) from the same patients were used as inputs for the pattern identification analysis. The weights were assigned based on the correlation between these 2 parameters. Parallel ICA was performed, and distinct covarying lesion patterns of cortical atrophy and WM lesions were identified. For each lesion pattern, the component loads of each patient related to cortical atrophy (brown line) and WM lesion volume (green line) were correlated. FLAIR = fluid-attenuated inversion recovery; ICA = independent component analysis; $\mathrm{T} 1 \mathrm{~W}=\mathrm{T} 1$ weighted; $\mathrm{T} 2 \mathrm{~W}=\mathrm{T} 2$-weighted; $\mathrm{WM}=$ white matter. intrinsic functional boundaries of the cerebellar-cortical networks. The previously obtained cerebellar pattern was projected onto this atlas to identify specific functionally interacting cerebellar networks. The extent of the involvement of each cerebellar-cortical network was quantified based on the absolute number of voxels (the threshold was set to $>10$ voxels; $p<0.05$ ) within each network and the relative size occupied by these voxels from the respective whole network.

\section{Individual-level support vector machine analysis}

The component loads of the lesion volumes for each individual patient were determined from the identified significant covarying patterns. These component loads for each lesion pattern were used as predictors of disease progression (as assessed by the EDSS score at 1-year follow-up) for each individual patient using a machine learning algorithm, the support vector machine (SVM). The details of the applied SVM algorithm are presented only for the study relevant terms, whereas the full information is available elsewhere. ${ }^{30}$ In short, the SVM algorithm is able to classify 2 data sets based on an optimally separating threshold between the data sets by maximizing the margin between classes' closest points. The points, which are located on the boundaries, are called support vectors, and the middle of the margin is the optimal separating threshold. For an effective linear separation of data points, a projection into a higherdimensional space is required (here, by means of polynomial function kernel). At the validation step, the component loads were assessed for the ability to automatically distinguish between the patients with and without disability progression. The classification was conducted for each lesion pattern separately. 


\section{Statistical analysis}

Summary statistics are presented as mean $\pm \mathrm{SD}$, median (range), or number (percentage), where applicable. The paired $t$ test was used for parametric scale and the Wilcoxon signedrank test for nonparametric scale variables. All statistical analyses were performed with Statistical Package for the Social Sciences 20.0 software (IBM, Armonk, NY) and MATLAB $\mathrm{R} 2015 \mathrm{~b}$ (MathWorks). To account for a possible influence on cortical atrophy rates, age and sex of the patients were included as covariates. To investigate whether the detected lesion topology patterns allow the prediction of physical disability (measured with the EDSS) on the group level, a receiver operating characteristic (ROC) analysis was conducted. This statistical method is preferentially used to quantify how accurately a diagnostic test performs when it is required to make a series of discriminations into 2 different states (e.g., stable EDSS and EDSS worsening) on the basis of a specific diagnostic variable (e.g., lesion pattern). The area under the ROC curve was used as the index of the prediction accuracy to compare the ROC curves. A $p$ value of $<0.05$ was considered statistically significant. For each significant covarying pattern that was used for the prediction of the EDSS score at follow-up, the accuracy was 10-fold cross-validated using the SVM algorithm.

\section{Data availability}

The raw data analyzed during this study will be shared in anonymized format by request of a qualified investigator to the corresponding author for purposes of replicating procedures and results.

\section{Results}

\section{Patients}

Demographic, clinical, and MRI characteristics of the patients from the study cohort are presented in table 1. The study cohort included 119 patients with RRMS (81 women) with a mean age of $34.6 \pm 9.8$ years and a mean disease duration of $37.2 \pm 25.0$ months. In total, 104 patients $(87 \%)$ received disease-modifying treatment, and 15 patients (13\%) had no disease-modifying treatment. During the 1-year follow-up, 12 patients (10\%) presented clinical relapse, 23 (19\%) had MRI activity, and 10 (9\%) presented both; the remaining 74 patients (62\%) were clinically and radiologically stable. Twenty-five patients $(21 \%)$ were considered to have disease progression after the 1-year follow-up period (maximum increase: 1.0 increase in the EDSS score). At follow-up, T2 lesion volume was significantly increased $(t=2.3, p<0.05)$, and global GM volume was significantly decreased $(t=2.1, p<0.05)$ when compared with baseline.

The replication cohort comprised 81 patients (mean age $35.5 \pm$ 10.9 years, 57 females) with a disease duration of $44.1 \pm 10.5$ months (table 1). Within this cohort, 50 patients $(75 \%)$ were on disease-modifying therapy, and 31 patients $(25 \%)$ were not taking any disease-modifying medication. In the course of 1-year period, 9 patients (11\%) presented clinical relapse or MRI activity, and 72 patients (89\%) were clinically and radiologically stable. After 1 year, 11 patients (14\%) had progression in their EDSS scores (maximum increase: 1.5 increase in the EDSS scores). At 1 year, patients from the replication cohort as those from the study cohort displayed reduced global GM volume $(\mathrm{t}=2.2, p<0.05)$.

Notably, there were no significant differences in mean EDSS scores between baseline and follow-up, neither in the study cohort $(p=0.51)$ nor in the replication cohort $(p=0.14)$. By comparison between the 2 cohorts (table e-1, links.lww.com/ NXI/A196), there were no significant differences in the patients' clinical and MRI characteristics (all $p$ values $>0.05$ ), except for disease duration being longer in the replication cohort (37.2 vs 44.1 months; $p<0.001)$.

\section{Covarying patterns of WM lesions and regional cortical atrophy}

The WM lesion distributions and regional cortical atrophy maps determined from 119 MRI data sets of the study cohort were included as 2 inputs into a parallel ICA. The analysis showed 3 significant covarying lesion patterns, namely a cerebellar pattern $(\mathrm{r}=0.68, p<0.001)$, a bihemispheric pattern $(\mathrm{r}=$ $0.61, p<0.001)$, implicating both hemispheres, and a leftlateralized pattern $(\mathrm{r}=0.58, p<0.001)$, affecting predominantly the left hemisphere (figure 2 ).

Similarly, we juxtaposed the lesion and atrophy maps in the replication cohort that were then fed into a parallel ICA. Here, the correlation analyses revealed 2 significant covarying lesion patterns: cerebellar $(\mathrm{r}=0.64, p<0.001)$ with a similar lesion distribution, located bilaterally in the cerebellum, and left-lateralized $(\mathrm{r}=0.62, p<0.001)$, involving mainly the hemisphere WM (figure e-1, links.lww.com/NXI/A193).

Covarying regional atrophy representations were in addition analyzed by subdividing the main cohort $(\mathrm{n}=119)$ into 2 subgroups dependent on the lesion load for each distinct pattern (below vs above the median). These groups were comparable in terms of global cortical atrophy rates (cerebellar $[\mathrm{t}=1.35, p>$ $0.05]$, bihemispheric $[\mathrm{t}=1.18, p>0.05]$, and left-lateralized [ $\mathrm{t}=$ $0.89, p>0.05]$ ). Regional atrophy distribution for each pattern is presented in figure e-2 (links.lww.com/NXI/A194) and table e-2 (links.lww.com/NXI/A196). None of the patterns was associated with the global cortical atrophy (Pearson correlation analysis, $p>0.05$ for all patterns) in both cohorts.

\section{Covarying patterns predict disease progression over time}

We performed ROC analyses (figure 3) to determine the predictive ability of distinct patterns (GM and WM pathology covariates) to discriminate patients with disability progression (based on patients' increase in the EDSS score by $\geq 1$ point at follow-up). The area under the curve (AUC) was 0.82 (95\% CI: $0.73-0.91$ ), specificity $79 \%$ and sensitivity $81 \%$ for the cerebellar pattern, the AUC was 0.66 (95\% CI: $0.54-0.77$ ), specificity $62 \%$ 
Table 1 Demographic, clinical, and MRI-derived measures of the study and replication cohorts

\begin{tabular}{|c|c|c|c|c|}
\hline Parameter & Baseline & Follow-up & $\mathrm{z} / \mathrm{t}^{\mathrm{b}}$ & $p$ Value \\
\hline \multicolumn{5}{|l|}{ Study cohort } \\
\hline \multicolumn{5}{|l|}{$\begin{array}{l}\text { Demographic and clinical } \\
\text { characteristics }\end{array}$} \\
\hline Age (y) & $34.6 \pm 9.8$ & & & \\
\hline Male/female: number (\%) & $38(32 \%) / 81(68 \%)$ & & & \\
\hline Disease duration (mo) & $37.2 \pm 25.0$ & & & \\
\hline EDSS score ${ }^{a}$ & $1.5(0-6.5)$ & $1.5(0-6.5)$ & 0.6 & 0.51 \\
\hline Follow-up (mo) & & $12.0 \pm 1.1$ & & \\
\hline \multicolumn{5}{|l|}{ MRI characteristics } \\
\hline GM volume $(\mathrm{mL})$ & $627.7 \pm 58.9$ & $622.9 \pm 55.0$ & 2.1 & 0.04 \\
\hline WM volume (mL) & $568.9 \pm 58.7$ & $568.6 \pm 55.0$ & 0.1 & 0.92 \\
\hline T2 lesion volume $(\mathrm{mL})$ & $7.3 \pm 12.1$ & $7.7 \pm 12.3$ & 2.3 & 0.02 \\
\hline \multicolumn{5}{|l|}{ Replication cohort } \\
\hline \multicolumn{5}{|l|}{$\begin{array}{l}\text { Demographic and clinical } \\
\text { characteristics }\end{array}$} \\
\hline Age (y) & $35.5 \pm 10.9$ & & & \\
\hline Male/female: number (\%) & $24(30 \%) / 57(70 \%)$ & & & \\
\hline Disease duration (mo) & $44.1 \pm 10.5$ & & & \\
\hline EDSS score ${ }^{a}$ & $1.0(0-6.5)$ & $1.5(0-6.5)$ & 1.4 & 0.14 \\
\hline Follow-up (mo) & & $12.7 \pm 5.7$ & & \\
\hline \multicolumn{5}{|l|}{ MRI characteristics } \\
\hline GM volume (mL) & $675.2 \pm 123.0$ & $672.0 \pm 122.0$ & 2.2 & 0.02 \\
\hline WM volume $(\mathrm{mL})$ & $516.2 \pm 95.9$ & $516.6 \pm 96.3$ & 0.4 & 0.66 \\
\hline T2 lesion volume (mL) & $6.3 \pm 11.0$ & $6.2 \pm 9.9$ & 0.6 & 0.48 \\
\hline
\end{tabular}

Abbreviations: EDSS = Expanded Disability Status Scale; GM = gray matter; $W M=$ white matter.

Values presented as mean \pm SD.

Significant $p$ values $(p<0.05)$ are shown in bold

a Median (range).

${ }^{\mathrm{b}}$ Wilcoxon signed-rank (Z) or paired $t$ test $(\mathrm{t})$ between baseline and follow-up values.

and sensitivity $59 \%$ for the bihemispheric pattern, and the AUC was 0.64 (95\% CI: $0.52-0.75$ ), specificity $63 \%$ and sensitivity $59 \%$ for the left-lateralized pattern (table e-3, links.lww.com/ NXI/A196). The cerebellar pattern therefore showed the best predictive performance of the 3 patterns in discriminating the patients with and without disability progression over time. A pairwise comparison of the ROC curves revealed a significant difference between the AUC of the cerebellar pattern and bihemispheric $(p<0.05)$ and left-lateralized $(p<0.05)$ patterns, respectively.

Analysis in the replication cohort supported these results. Using the ROC analysis, we found that the AUC was 0.86 (95\% CI: $0.76-0.94)$, specificity $83 \%$ and sensitivity $88 \%$ for the cerebellar pattern, and the AUC was 0.66 (95\% CI: 0.55-0.77), specificity $61 \%$ and sensitivity $63 \%$ for the left-lateralized pattern in this cohort (figure e-3, links.lww.com/NXI/A195 and table e-3, links.lww.com/NXI/A196).

In both cohorts, predictive accuracy derived from the integration of both WM lesions and cortical atrophy patterns outperforms the predictive accuracy of one of both patterns alone. The comparative ROC characteristics are shown in table e-3 (links.lww.com/NXI/A196).

The map of the cerebellar lesion distribution is shown in figure 4A for the predictive power. Here, each particular voxel shows how this region contributes to the prediction analyses for disease progression (patients with vs without disease progression). This SVM-based individual patient prediction analysis achieved as well the best cross-validated accuracy of $88 \%$ for the cerebellar and of $75 \%$ for the bihemispheric and 
A

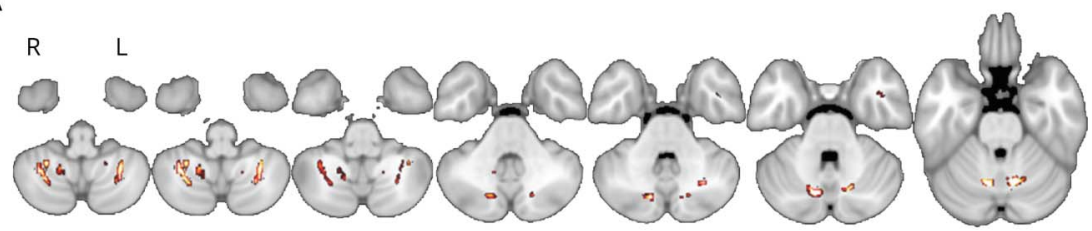

B

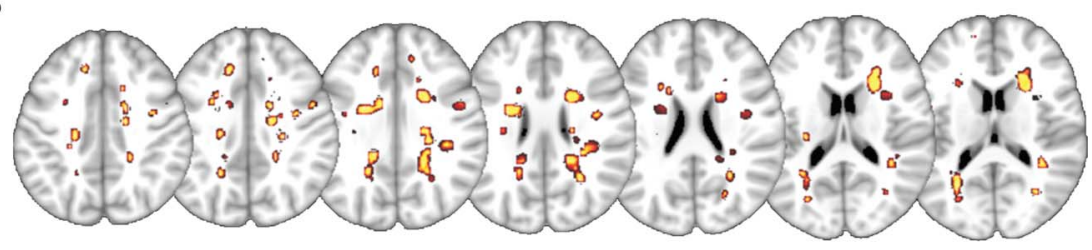

$\mathrm{C}$

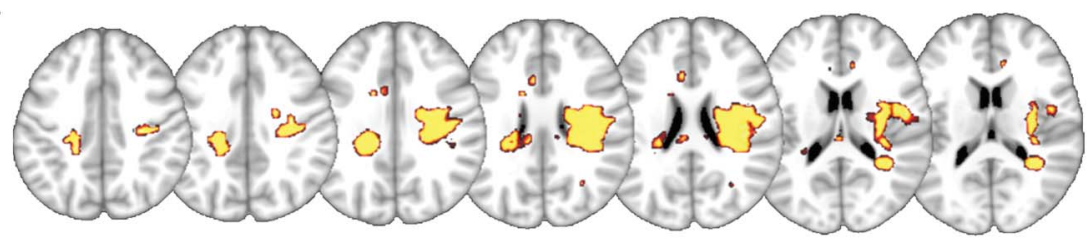

(A) Cerebellar lesion pattern, (B) bihemispheric lesion pattern, and (C) left-lateralized lesion pattern. WM = white matter.

$64 \%$ for the left-lateralized pattern in predicting disease progression at 1-year follow-up (table e-4, links.lww.com/NXI/ A196). In the replication cohort, the SVM-based individual

Figure 3 Comparison of ROC curves showing the accuracy of covarying lesion patterns in predicting disability progression

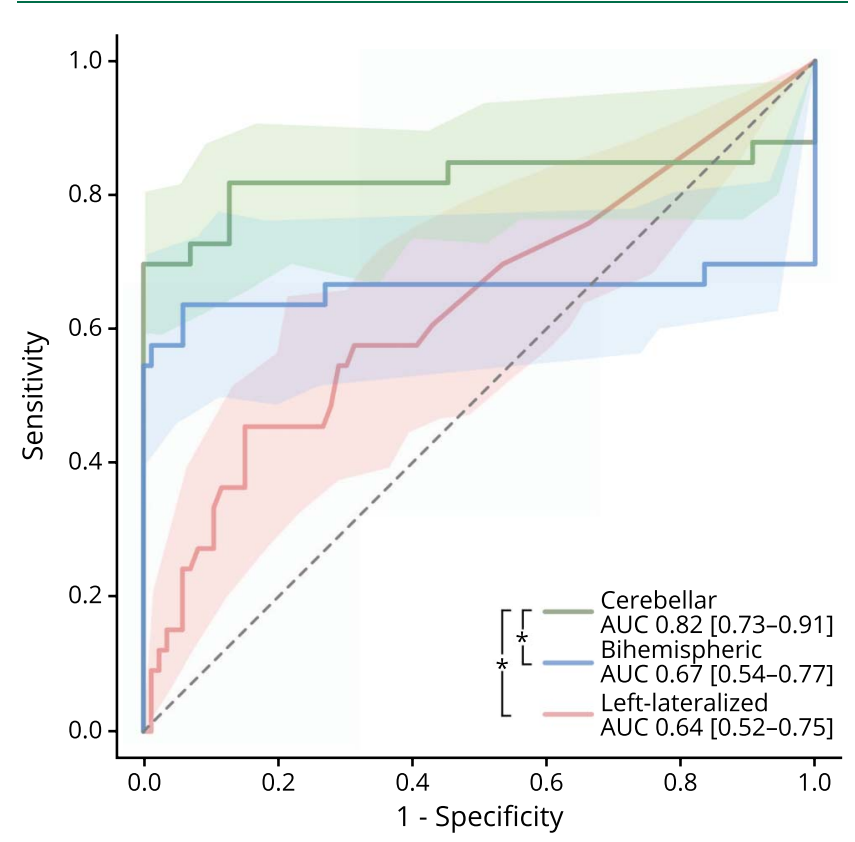

The shadowed areas represent the $95 \% \mathrm{Cls}$. In the legend, the AUC and the $95 \%$ Cls are presented. The cerebellar pattern shows the best accuracy in predicting disability progression over time in comparison to the bihemispheric and left-lateralized patterns $\left({ }^{*} p<0.05\right)$. AUC $=$ area under the curve. analysis achieved the best cross-validated accuracy of $89 \%$ for the cerebellar and $66 \%$ for the left-lateralized patterns in predicting the disease progression over 1 year (table e-4, links.lww. com/NXI/A196).

While projecting the lesion maps of the cerebellar pattern onto the Buckner connectivity atlas (figure 4, C and D), we depict the involvement of 4 major cerebellar networks in both cohorts (study/replication cohort), namely frontoparietal (relative size, range 5.0-27.4\%/5.8-25\%), default mode (4.2-8.2\%/6.0-8.0\%), somatomotor (3.1-5.5\%/2.9-4.9\%), and ventral attention $(2.8-6.4 \% / 2.4-5.2 \%)$ network.

\section{Discussion}

In this work, we investigated covarying patterns of GM and WM tissue damage in patients with early RRMS and studied the impact of these patterns on MS disease progression. We identified 3 covarying patterns of WM lesions and regional cortical atrophy. All 3 patterns predicted short-term disease progression with clinical impairment robustly, but with different accuracies. The cerebellar pattern was related to a more widespread, mainly frontotemporal cortical atrophy and had the strongest prediction accuracy of the 3 patterns. Because the cerebellum is functionally segregated and integrated in various functional networks including interconnected subcortical and cortical areas, a deafferentation-driven pathology secondary to lesions in cortico-ponto-cerebellar pathways could be postulated. Our results suggest that cerebellar inflammation seems to amplify other pathologic mechanisms, such as retrograde neurodegeneration of cortical areas even far away from the 
A

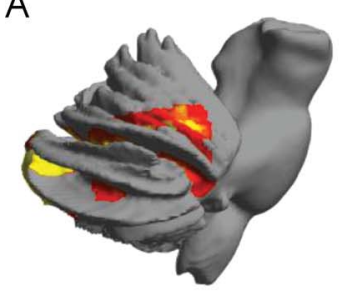

B

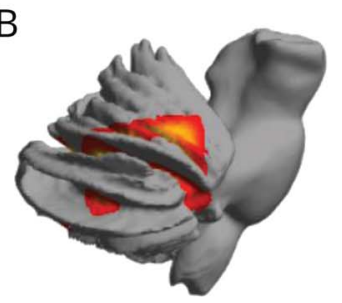

C

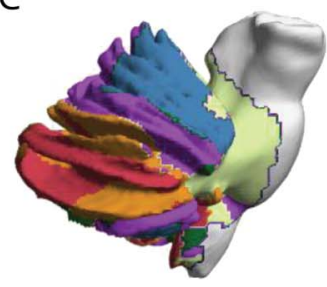

D

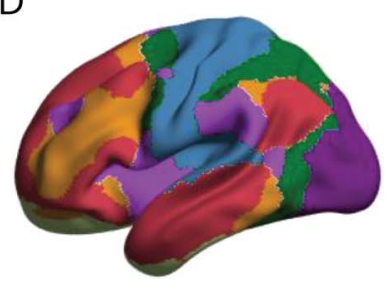

0.1
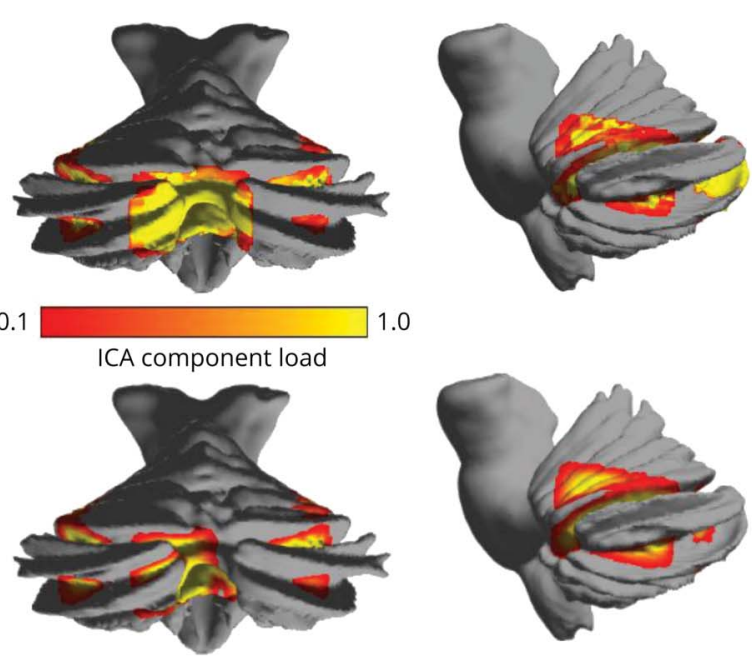

1.0
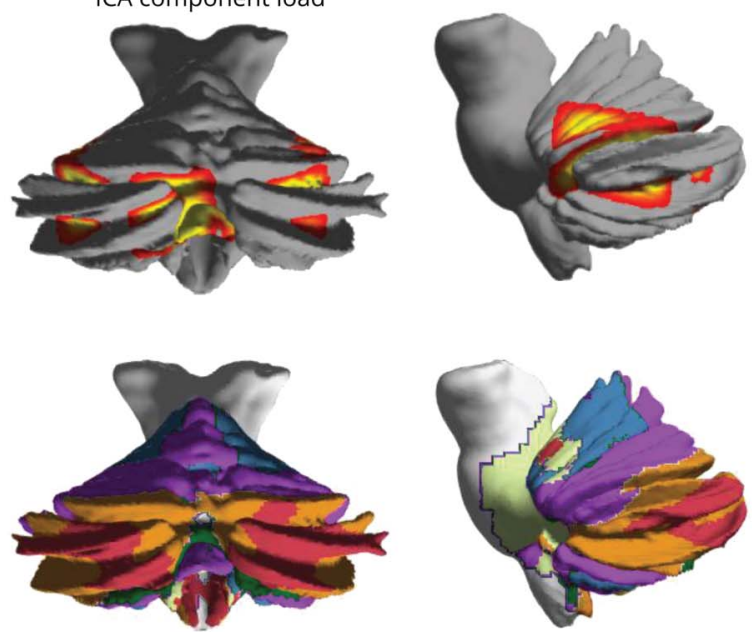

Default

Frontoparietal

Limbic

Ventral attention

Dorsal attention

Somatomotor

Visual
Here, each particular voxel shows how this region contributes to the prediction analysis for disease progression in the study cohort (A) and in the replication cohort (B). Color bar indicates the component load of the cerebellar pattern. (C) shows the Buckner 7-network cerebellar nuclei atlas, and (D) represents the corresponding cortical connectivity map. ICA = independent component analysis. lesion site (as demonstrated by the covarying atrophy pattern in our study), presumably via long-ranging connections that were recently shown to be more severely damaged than shortrange connections. ${ }^{31}$

Previous neuroimaging and histopathologic studies have shown that both GM and WM compartments are affected early in the disease course of MS. ${ }^{32,33}$ However, it was still unclear whether GM atrophy and WM damage occur randomly, are interrelated, or follow specific anatomical or sequential patterns and, in particular, whether the topographical distribution is relevant for early clinical disability. Few new studies have addressed either the patterns of WM damage ${ }^{8}$ or GM atrophy. ${ }^{9,10}$ Steenwijk et al. ${ }^{9}$ depicted 10 different nonrandom patterns of cortical atrophy in patients with long-standing MS (disease duration $>20$ years): 4 were associated with the functional disability (quantified by the EDSS score) at the time point of the investigation. The cortical atrophy patterns showed stronger associations with clinical, in particular cognitive, dysfunction than global cortical atrophy. The detected patterns that showed most pronounced cortical atrophy were located in the bilateral posterior cingulate cortex and the bilateral temporal pole. In particular, the marked cortical atrophy of the temporal lobe is in line with our findings reporting that the cerebellar pattern is predominantly related to atrophy of the superior temporal lobe and the cortical areas around superior temporal sulcus. In contrast to their findings, we found that all our detected lesion patterns comprised-at least partly-cortical atrophy in the parietal lobe being responsible for sensory information among various modalities, including spatial sense and proprioception, which is typically affected already in patients with early-stage MS as in our cohorts. The study by Steenwijk et al. provided the first evidence that spatial distribution of GM damage is relevant for clinical disability in MS. However, it was limited by its crosssectional nature, clinically heterogeneous MS population (i.e., RRMS and primary and secondary progressive MS), and the exclusion of subcortical and cerebellar GM.

In our study, we were able to identify 3 covarying patterns of spatially distributed damage in a cohort consisting of only 
patients with early RRMS who were evaluated in a longitudinal approach. Our findings indicate that these patterns are clinically relevant and allow prediction of disease progression and emerging functional impairment in 2 early and mildly affected RRMS cohorts. We suggest that in early RRMS, the patterns of GM and WM pathology distribution reflect network organization. ${ }^{34,35}$ Our recent work has shown that such GM and WM network characteristics are essential for the maintenance of function through structural adaptation despite global long-range disconnection..$^{30,34}$ In particular, at early stages, the GM and WM display similar structural reorganization dynamics with strengthening of local connectivity, whereas at later disease stages, the divergence in network patterns is associated with clinical deterioration. ${ }^{34,36}$

Our findings support the hypothesis that the distribution of GM and WM damage is interrelated because we demonstrated correlative links between WM lesion patterns and localization of cortical atrophy by parallel ICA. We further showed that the global cortical atrophy was independent of the lesion pattern phenotype and not related to clinical deterioration in the short time investigated here. The cerebellar pattern shows most extensive spreading of cortical atrophy and particularly with cortical thickness reduction in the frontal and temporal lobes. The bihemispheric pattern contains increased atrophy in the orbitofrontal cortex, whereas the left-lateralized pattern covered fusiform, superior frontal and parietal cortical areas. The lack of an association between the lesion volume within each pattern and the global rate of cortical atrophy highlights the importance of the spatial distribution of cortical GM and WM damage and shows that the simple notion that more tissue damage necessarily leads to more clinical disability is too narrow. A recent neuropathologic study investigating the relationship between GM and WM damage postulated that cortical inflammation and damage might drive the underlying WM pathology through abnormal neuronal activity and decreased input from the affected areas. ${ }^{37}$ The authors provided evidence of direct interlesional connectivity between cortical and WM lesions, in line with our findings that the interplay of both compartments influences disease progression.

Although infratentorial pathology was reported to increase the risk of disability, ${ }^{14}$ we here provide compelling evidence that individual-level SVM analysis of the cerebellar lesion pattern in conjunction with mainly frontotemporal cortical atrophy could be used to predict disability progression from the early disease stages with high accuracy. This could be used to build prediction models in an intersite setting and is of special clinical relevance for tracking disease courses or therapeutic responses. We found the cerebellar pattern to be associated with higher atrophy rates in the superior temporal, frontal, and parietal cortex, most of which is essential for motor and cognitive performance. Indeed, specific reorganization of cerebellocortical networks is already evident in patients with clinically isolated syndrome and early RRMS ${ }^{30}$ and might represent an adaptive response to maintain motor function. Breakdown of these networks, on the other hand, could lead to long-term functional impairment or even be related to the transition into progressive form of the disease. In addition, the cerebellar circuits undergo functional and structural reorganization with increasing clinical disability ${ }^{30,34}$ and are more prominent in progressive $M S .^{38,39}$

Some limitations apply to this work. Although both cohorts were well matched on age, sex, and clinical disability, the cohorts significantly differed in their disease duration. However, the absolute difference of approximately 6 months between both cohorts is clinically negligible, as patients in both cohorts are clearly in the early relapsing-remitting phase of the disease. Slight differences in some of the MRI acquisition parameters between the 2 cohorts could have influenced the generation of the patterns, although key acquisition parameters determining resolution were identical in both cohorts.

Another limitation is the relatively short follow-up time of 1 year, as changes in the brain usually occur on a larger timescale as changes on the EDSS score. However, cortical thinning as estimated in our study has shown to occur already early in the disease and was repeatedly detectable in 1-year intervals. ${ }^{40}$ On the other side, the EDSS score is limited by its poor assessment of upper limb function and cognitive decline, which is captured better in other outcome measures like the MS Functional Composite. ${ }^{41}$ However, despite its disadvantages, it is still the most established score for evaluating MS progression in clinical trials. Finally, only $21 \%$ within the main study cohort and $14 \%$ within the replication cohort had proven disability progression, which is indeed in line with other 1-year progression data, ${ }^{42}$ but resulted in a low absolute number of patients in our study and hence reduced the power of the statistical analysis.

Our approach, combining GM and WM imaging and correlating these with disease progression, fills the gap in our understanding between the functional consequences of structural damage in the cerebellum and their predictive value in patients with MS. Future work should evaluate and validate the longterm (over years and decades) implications of our findings and investigate the potential for a combined GM and WM biomarker with broad clinical utility in patients with MS. Identification of MS imaging phenotypes with predominant signs of cerebellar dysfunction would further affect early therapeutic strategies potentially pointing to prevent a worse prognosis.

Taken together, we have shown that distinct damage distribution patterns in both GM and WM compartments, rather than a broad random effect, characterize upcoming disability progression in the first year after onset of MS. Lesion topology strongly affects regional cortical integrity through interconnected structural networks and accurately predicts the short-term progression of individual patient disability. Early recognition and timely surveillance of lesion patterns at initial stages of the disease might be clinically applicable to identify patients at higher risk of cortical atrophy and worse clinical outcome and who would therefore most benefit from prompt therapeutic intervention. 


\section{Acknowledgment}

The authors thank Cheryl Ernest and Rosalind Gilchrist for proofreading the manuscript.

\section{Study funding}

This study has been supported by the German Research Foundation (DFG; CRC-TR-128).

\section{Disclosure}

M. Muthuraman, V. Fleischer, J. Kroth, D. Ciolac, A. Radetz, N. Koirala, G. Gonzalez-Escamilla, and S. Groppa report no disclosures relevant to the manuscript. $\mathrm{H}$. Wiendl receives honoraria for acting as a member of scientific advisory boards and as a consultant for Biogen, Evgen, MedDay Pharmaceuticals, Merck Serono, Novartis, Roche Pharma AG, Sanofi Genzyme and speaker honoraria and travel support from Alexion, Biogen, Cognomed, F. Hoffmann-La Roche Ltd., Gemeinnützige Hertie-Stiftung, Merck Serono, Novartis, Roche Pharma AG, Sanofi Genzyme, Teva, and WebMD Global. Prof. Wiendl is acting as a paid consultant for AbbVie, Actelion, Biogen, IGES, Novartis, Roche, Sanofi-Genzyme, and the Swiss Multiple Sclerosis Society. His research is funded by the BMBF, DFG, Else Kröner Fresenius Foundation, Fresenius Foundation, Hertie Foundation, NRW Ministry of Education and Research, Interdisciplinary Center for Clinical Studies (IZKF) Muenster and RE Children's Foundation, Biogen GmbH, GlaxoSmithKline GmbH, Roche Pharma AG, and Sanofi Genzyme. S.G. Meuth has received honoraria for lecturing, travel expenses for attending meetings, and financial research support from Almirall, Amicus Therapeutics $\mathrm{GmbH}$ Deutschland, Bayer Health Care, Biogen, Celgene, Diamed, Genzyme, MedDay Pharmaceuticals, Merck Serono, Novartis, Novo Nordisk, ONO Pharma, Roche, SanofiAventis, Chugai Pharma, QuintilesIMS, and Teva. F. Zipp has recently received research grants and/or consultation funds from DFG, BMBF, PMSA, MPG, Genzyme, Merck Serono, Roche, Novartis, Sanofi-Aventis, Celgene, ONO, and Octapharma. Go to Neurology.org/NN for full disclosures.

\section{Publication history}

Received by Neurology: Neuroimmunology \& Neuroinflammation July 11, 2019. Accepted in final form January 7, 2020.

Appendix Authors

\begin{tabular}{|c|c|c|c|}
\hline Name & Location & Role & Contribution \\
\hline $\begin{array}{l}\text { Muthuraman } \\
\text { Muthuraman, } \\
\text { PhD }\end{array}$ & $\begin{array}{l}\text { University Medical } \\
\text { Center of the } \\
\text { Johannes } \\
\text { Gutenberg } \\
\text { University Mainz, } \\
\text { Germany }\end{array}$ & Author & $\begin{array}{l}\text { Design and } \\
\text { conceptualization of } \\
\text { the study; acquisition } \\
\text { and analysis of data; } \\
\text { and drafting } \\
\text { significant } \\
\text { proportion of the } \\
\text { manuscript }\end{array}$ \\
\hline
\end{tabular}

Appendix (continued)

\begin{tabular}{|c|c|c|c|}
\hline Name & Location & Role & Contribution \\
\hline $\begin{array}{l}\text { Vinzenz } \\
\text { Fleischer, MD }\end{array}$ & $\begin{array}{l}\text { University Medical } \\
\text { Center of the } \\
\text { Johannes } \\
\text { Gutenberg } \\
\text { University Mainz, } \\
\text { Germany }\end{array}$ & Author & $\begin{array}{l}\text { Design and } \\
\text { conceptualization of } \\
\text { the study; acquisition } \\
\text { and analysis of data; } \\
\text { and drafting } \\
\text { significant } \\
\text { proportion of the } \\
\text { manuscript }\end{array}$ \\
\hline $\begin{array}{l}\text { Julia Kroth, } \\
\text { MD }\end{array}$ & $\begin{array}{l}\text { University Medical } \\
\text { Center of the } \\
\text { Johannes } \\
\text { Gutenberg } \\
\text { University Mainz, } \\
\text { Germany }\end{array}$ & Author & $\begin{array}{l}\text { Design and } \\
\text { conceptualization of } \\
\text { the study; acquisition } \\
\text { and analysis of data; } \\
\text { and drafting } \\
\text { significant } \\
\text { proportion of the } \\
\text { manuscript }\end{array}$ \\
\hline $\begin{array}{l}\text { Dumitru } \\
\text { Ciolac, MD }\end{array}$ & $\begin{array}{l}\text { University Medical } \\
\text { Center of the } \\
\text { Johannes } \\
\text { Gutenberg } \\
\text { University Mainz, } \\
\text { Germany }\end{array}$ & Author & $\begin{array}{l}\text { Acquisition and } \\
\text { analysis of the data } \\
\text { and revision of the } \\
\text { manuscript for } \\
\text { intellectual content }\end{array}$ \\
\hline $\begin{array}{l}\text { Angela } \\
\text { Radetz, MSc }\end{array}$ & $\begin{array}{l}\text { University Medical } \\
\text { Center of the } \\
\text { Johannes } \\
\text { Gutenberg } \\
\text { University Mainz, } \\
\text { Germany }\end{array}$ & Author & $\begin{array}{l}\text { Acquisition and } \\
\text { analysis of the data }\end{array}$ \\
\hline $\begin{array}{l}\text { Nabin Koirala, } \\
\text { PhD }\end{array}$ & $\begin{array}{l}\text { University Medical } \\
\text { Center of the } \\
\text { Johannes } \\
\text { Gutenberg } \\
\text { University Mainz, } \\
\text { Germany }\end{array}$ & Author & $\begin{array}{l}\text { Acquisition and } \\
\text { analysis of the data }\end{array}$ \\
\hline $\begin{array}{l}\text { Gabriel } \\
\text { Gonzalez- } \\
\text { Escamilla, PhD }\end{array}$ & $\begin{array}{l}\text { University Medical } \\
\text { Center of the } \\
\text { Johannes } \\
\text { Gutenberg } \\
\text { University Mainz, } \\
\text { Germany }\end{array}$ & Author & $\begin{array}{l}\text { Acquisition and } \\
\text { analysis of the data }\end{array}$ \\
\hline $\begin{array}{l}\text { Heinz Wiendl, } \\
\text { MD }\end{array}$ & $\begin{array}{l}\text { University of } \\
\text { Munster, Germany }\end{array}$ & Author & $\begin{array}{l}\text { Analysis and } \\
\text { interpretation of the } \\
\text { data and revision of } \\
\text { the manuscript for } \\
\text { intellectual content }\end{array}$ \\
\hline $\begin{array}{l}\text { Sven G. } \\
\text { Meuth, PhD, } \\
\text { MD }\end{array}$ & $\begin{array}{l}\text { University of } \\
\text { Munster, Germany }\end{array}$ & Author & $\begin{array}{l}\text { Analysis and } \\
\text { interpretation of the } \\
\text { data and revision of } \\
\text { the manuscript for } \\
\text { intellectual content }\end{array}$ \\
\hline $\begin{array}{l}\text { Frauke Zipp, } \\
\text { MD }\end{array}$ & $\begin{array}{l}\text { University Medical } \\
\text { Center of the } \\
\text { Johannes } \\
\text { Gutenberg } \\
\text { University Mainz, } \\
\text { Germany }\end{array}$ & Author & $\begin{array}{l}\text { Design and } \\
\text { conceptualization of } \\
\text { the study; acquisition } \\
\text { and analysis of data; } \\
\text { and drafting } \\
\text { significant } \\
\text { proportion of the } \\
\text { manuscript }\end{array}$ \\
\hline $\begin{array}{l}\text { Sergiu } \\
\text { Groppa, MD }\end{array}$ & $\begin{array}{l}\text { University Medical } \\
\text { Center of the } \\
\text { Johannes } \\
\text { Gutenberg } \\
\text { University Mainz, } \\
\text { Germany }\end{array}$ & Author & $\begin{array}{l}\text { Design and } \\
\text { conceptualization of } \\
\text { the study; acquisition } \\
\text { and analysis of data; } \\
\text { and drafting } \\
\text { significant } \\
\text { proportion of the } \\
\text { manuscript }\end{array}$ \\
\hline
\end{tabular}




\section{References}

1. Siffrin V, Vogt J, Radbruch H, Nitsch R, Zipp F. Multiple sclerosis-candidate mechanisms underlying CNS atrophy. Trends Neurosciences 2010;33:202-210.

2. Zipp F, Gold R, Wiendl H. Identification of inflammatory neuronal injury and prevention of neuronal damage in multiple sclerosis: hope for novel therapies? JAMA Neurol 2013;70:1569-1574.

3. Pitteri M, Romualdi C, Magliozzi R, Monaco S, Calabrese M. Cognitive impairment predicts disability progression and cortical thinning in MS: an 8-year study. Mult Scler 2017;23:848-854.

4. Fisher E, Lee JC, Nakamura K, Rudick RA. Gray matter atrophy in multiple sclerosis: a longitudinal study. Ann Neurol 2008;64:255-265.

5. Jacobsen C, Hagemeier J, Myhr KM, et al. Brain atrophy and disability progression in multiple sclerosis patients: a 10-year follow-up study. J Neurol Neurosurg Psychiatry 2014;85:1109-1115.

6. Galassi S, Prosperini L, Logoteta A, et al. A lesion topography-based approach to predict the outcomes of patients with multiple sclerosis treated with Interferon Beta. Mult Scler Relat Disord 2016;8:99-106.

7. Fisniku LK, Chard DT, Jackson JS, et al. Gray matter atrophy is related to long-term disability in multiple sclerosis. Ann Neurol 2008;64:247-254.

8. Meijer K, Cercignani M, Muhlert N, et al. Patterns of white matter damage are nonrandom and associated with cognitive function in secondary progressive multiple sclerosis. Neuroimage Clin 2016;12:123-131.

9. Steenwijk MD, Geurts JJ, Daams M, et al. Cortical atrophy patterns in multiple sclerosis are non-random and clinically relevant. Brain 2016;139:115-126.

10. Bergsland N, Horakova D, Dwyer MG, et al. Gray matter atrophy patterns in multiple sclerosis: a 10-year source-based morphometry study. Neuroimage Clin 2018;17: 444-451.

11. Gupta CN, Chen J, Liu J, et al. Genetic markers of white matter integrity in schizophrenia revealed by parallel ICA. Front Hum Neurosci 2015;9:100.

12. Coppen EM, van der Grond J, Hafkemeijer A, Rombouts SA, Roos RA. Early grey matter changes in structural covariance networks in Huntington's disease. Neuroimage Clin 2016;12:806-814.

13. Popescu V, Agosta F, Hulst HE, et al. Brain atrophy and lesion load predict long term disability in multiple sclerosis. J Neurol Neurosurg Psychiatry 2013;84:1082-1091.

14. Minneboo A, Barkhof F, Polman CH, Uitdehaag BM, Knol DL, Castelijns JA. Infratentorial lesions predict long-term disability in patients with initial findings suggestive of multiple sclerosis. Arch Neurol 2004;61:217-221.

15. Filippi M, Preziosa P, Copetti M, et al. Gray matter damage predicts the accumulation of disability 13 years later in MS. Neurology 2013;81:1759-1767.

16. Chard D, Miller D. Grey matter pathology in clinically early multiple sclerosis: evidence from magnetic resonance imaging. J Neurol Sci 2009;282:5-11.

17. Polman $\mathrm{CH}$, Reingold SC, Banwell B, et al. Diagnostic criteria for multiple sclerosis 2010 revisions to the McDonald criteria. Ann Neurol 2011;69:292-302.

18. Ellison GW, Myers LW, Leake BD, et al. Design strategies in multiple sclerosis clinical trials. The Cyclosporine Multiple Sclerosis Study Group. Ann Neurol 1994;36: S108-S112.

19. Schmidt P, Gaser C, Arsic M, et al. An automated tool for detection of FLAIRhyperintense white-matter lesions in multiple sclerosis. Neuroimage 2012;59: 3774-3783.

20. Reuter M, Rosas HD, Fischl B. Highly accurate inverse consistent registration: a robust approach. Neuroimage 2010;53:1181-1196.

21. Reuter M, Schmansky NJ, Rosas HD, Fischl B. Within-subject template estimation for unbiased longitudinal image analysis. Neuroimage 2012;61:1402-1418.
22. Pardoe HR, Abbott DF, Jackson GD; AsDN Initiative. Sample size estimates for wellpowered cross-sectional cortical thickness studies. Hum Brain Mapp 2013;34: 3000-3009.

23. Coalson TS, Van Essen DC, Glasser MF. The impact of traditional neuroimaging methods on the spatial localization of cortical areas. Proc Natl Acad Sci 2018;115: E6356-E6365.

24. Calhoun VD, Adali T, Giuliani NR, Pekar JJ, Kiehl KA, Pearlson GD. Method for multimodal analysis of independent source differences in schizophrenia: combining gray matter structural and auditory oddball functional data. Hum Brain Mapp 2006; 27:47-62.

25. Anemuller J, Sejnowski TJ, Makeig S. Complex independent component analysis of frequency-domain electroencephalographic data. Neural Netw 2003;16:1311-1323.

26. Liu J, Pearlson G, Windemuth A, Ruano G, Perrone-Bizzozero NI, Calhoun V. Combining fMRI and SNP data to investigate connections between brain function and genetics using parallel ICA. Hum Brain Mapp 2009;30:241-255.

27. Li YO, Adalı T, Calhoun VD. Estimating the number of independent components for functional magnetic resonance imaging data. Hum Brain Mapp 2007;28:1251-1266.

28. Buckner RL, Krienen FM, Castellanos A, Diaz JC, Yeo BT. The organization of the human cerebellum estimated by intrinsic functional connectivity. J Neurophysiol 2011;106:2322-2345.

29. Yeo BTT, Krienen FM, Sepulcre J, et al. The organization of the human cerebral cortex estimated by intrinsic functional connectivity. J Neurophysiol 2011;106: $1125-1165$

30. Muthuraman M, Fleischer V, Kolber P, Luessi F, Zipp F, Groppa S. Structural brain network characteristics can differentiate CIS from early RRMS. Front Neurosci 2016;10:14.

31. Meijer KA, Steenwijk MD, Douw L, Schoonheim MM, Geurts JJG. Long-range connections are more severely damaged and relevant for cognition in multiple sclerosis. Brain 2020;143:150-160.

32. Kutzelnigg A, Lucchinetti CF, Stadelmann C, et al. Cortical demyelination and diffuse white matter injury in multiple sclerosis. Brain 2005;128:2705-2712.

33. Calabrese M, Atzori M, Bernardi V, et al. Cortical atrophy is relevant in multiple sclerosis at clinical onset. J Neurol 2007;254:1212-1220.

34. Fleischer V, Groger A, Koirala N, et al. Increased structural white and grey matter network connectivity compensates for functional decline in early multiple sclerosis. Mult Scler 2017;23:432-441.

35. Fleischer V, Radetz A, Ciolac D, et al. Graph theoretical framework of brain networks in multiple sclerosis: a review of concepts. Neuroscience 2019;403:35-53.

36. Charalambous T, Tur C, Prados F, et al. Structural network disruption markers explain disability in multiple sclerosis. J Neurol Neurosurg Psychiatry 2019;90: 219-226.

37. Tillema JM, Weigand SD, Mandrekar J, et al. In vivo detection of connectivity between cortical and white matter lesions in early MS. Mult Scler J 2017;23:973-981.

38. Anderson V, Wheeler-Kingshott C, Abdel-Aziz K, et al. A comprehensive assessment of cerebellar damage in multiple sclerosis using diffusion tractography and volumetric analysis. Mult Scler J 2011;17:1079-1087.

39. Redondo J, Kemp K, Hares K, Rice C, Scolding N, Wilkins A. Purkinje cell pathology and loss in multiple sclerosis cerebellum. Brain Pathol 2015;25:692-700.

40. Koubiyr I, Deloire M, Coupe P, et al. Differential gray matter vulnerability in the 1 Year following a clinically isolated syndrome. Front Neurol 2018;9:824.

41. Rudick RA, Cutter G, Baier M, et al. Use of the multiple sclerosis functional composite to predict disability in relapsing MS. Neurology 2001;56:1324-1330.

42. Mesaros S, Rocca MA, Sormani MP, Charil A, Comi G, Filippi M. Clinical and conventional MRI predictors of disability and brain atrophy accumulation in RRMS. A large scale, short-term follow-up study. J Neurol 2008;255:1378-1383. 


\section{Neurology \\ Neuroimmunology \& Neuroinflammation}

\section{Covarying patterns of white matter lesions and cortical atrophy predict progression in early MS}

Muthuraman Muthuraman, Vinzenz Fleischer, Julia Kroth, et al.

Neurol Neuroimmunol Neuroinflamm 2020;7;

DOI 10.1212/NXI.0000000000000681

This information is current as of February 5, 2020

\section{Updated Information \& \\ Services}

References

Citations

Subspecialty Collections

Permissions \& Licensing

Reprints including high resolution figures, can be found at:

http://nn.neurology.org/content/7/3/e681.full.html

This article cites 42 articles, 4 of which you can access for free at: http://nn.neurology.org/content/7/3/e681.full.html\#\#ref-list-1

This article has been cited by 3 HighWire-hosted articles: http://nn.neurology.org/content/7/3/e681.full.html\#\#otherarticles

This article, along with others on similar topics, appears in the following collection(s):

Cerebellum

http://nn.neurology.org//cgi/collection/cerebellum

Multiple sclerosis

http://nn.neurology.org//cgi/collection/multiple_sclerosis

Information about reproducing this article in parts (figures,tables) or in its entirety can be found online at:

http://nn.neurology.org/misc/about.xhtml\#permissions

Information about ordering reprints can be found online:

http://nn.neurology.org/misc/addir.xhtml\#reprintsus

Neurol Neuroimmunol Neuroinflamm is an official journal of the American Academy of Neurology.

Published since April 2014, it is an open-access, online-only, continuous publication journal. Copyright

Copyright $\odot 2020$ The Author(s). Published by Wolters Kluwer Health, Inc. on behalf of the American

Academy of Neurology.. All rights reserved. Online ISSN: 2332-7812.

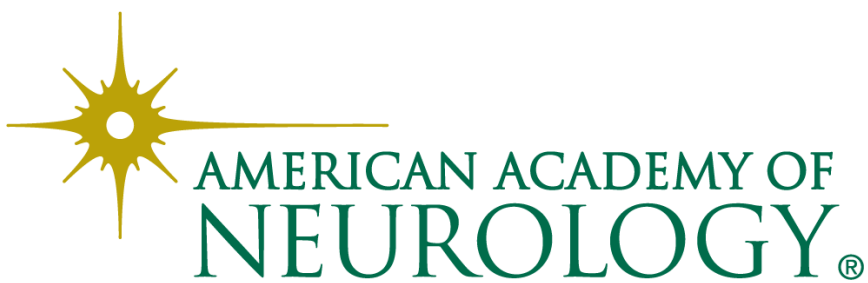

